\title{
Ventajas de Open Journal System y el acceso abierto a la Información
}

Fecha recibido: $22-06-17$ Fecha aceptado: 22-06-17
La Revista Colombiana de Gastroenterología ha dado un paso hacia la promoción de la investigación libre a través de su suscripción al sistema de revistas Open Journal System. Con ello se manifiesta la apuesta de la Revista de Gastroenterología por:

- Disponibilidad de un determinado contenido de forma gratuita y pública en la red, permitiendo la lectura, la descarga, copia, distribución, impresión, búsqueda o enlace a los textos completos, sin barreras económicas, legales o técnicas.

- Consolidación de la investigación nacional, por el aumento en la visibilidad e impacto de las publicaciones.

En cuanto al proceso editorial, este sistema ofrece ventajas significativas, entre ellas: plataforma web independiente, control de los envíos (manuscritos) por parte de los autores a la Revista, control de las versiones ( $y$, por tanto, mayor trasparencia en el proceso), avisos y mensajes automáticos, revista multilingüe y, en general, mayor facilidad y rapidez en la gestión editorial (con el consecuente ahorro de recursos). Adicionalmente, la integración con otros sistemas (Google, DOAJ, PubMed, entre otros).

En relación con esto, la Revista ha suscrito un acuerdo con CrossRef para la activación de objetos de identificación digital (DOI), que garantizarán la estabilidad en el tiempo de las publicaciones de la Revista. Con ello se asegura, por una parte, un sistema de referencias eficiente y, ante todo, el acceso continuo y directo a los artículos.

Les invitamos a visitar nuestra nueva página www.revistagastrocol.com y a registrarse en la misma en calidad de lector, autor o revisor de artículos.

Comité editorial Revista Colombiana de Gastroenterología 